Metoda Kemperl

\title{
Sodobna umetnost in obvezne izbirne vsebine $v$ gimnaziji
}

\begin{abstract}
Ključne besede: sodobna umetnost, participatorne likovne prakse, socialno angažirana umetnost, državljanska vzgoja, aktivno državljanstvo, obvezne izbirne vsebine, medpredmetno povezovanje
\end{abstract}

\section{Uvod}

Eden najbolj talentiranih in najbolj vplivnih raziskovalcev človekovega (predvsem otrokovega) spoznavnega razvoja Rus Lev S. Vigotski (1896-1934) je večkrat prestopal meje psihologije, vede, v katero ga največkrat uvrščajo, saj je bil zelo široko izobražen. Svojo pot na področju psihološkega raziskovanja je začel $s$ širokim znanjem s področij zgodovine, filozofije, umetnosti in jezikov. Ker se je ukvarjal z vplivom socialnega razreda na razvoj otrok, je Stalin dve leti po njegovi smrt prepovedal njegova dela in dal izbrisati njegovo ime iz znanstvenih revij. Šele leta 1956 so v Sovjetski zvezi spet dovolili objavljanje njegovih del, v zahodni Evropi in ZDA pa od sedemdesetih let 20. stoletja, ko so njegova ključna dela počasi začeli prevajati, zanimanje za njegovo teorijo strmo narašča (Marjanovič Umek, 2010; Gaber, 2010). Vigotski je leta 1925 doktoriral iz psihologije umetnosti in istega leta napisal knjigo Psihologija umetnosti, ki je bila v Sovjetski zvezi natisnjena šele leta 1968, na Zahodu pa je prvič izšla leta 1971. V delu je avtor prepoznal potencial umetnosti, ki lahko po njegovem mnenju spremeni posameznikovo vedênje in bogati izkušnje. $\mathrm{V}$ poglavju, v katerem se je spraševal o povezavi umetnosti in življenja, je zapisal, da se je na umetnost že od nekdaj gledalo tudi kot na del in sredstvo vzgoje in izobraževanja oziroma del dolgoročnega spreminjanja našega vedênja in obnašanja (Vigotski, 1975, 319). Kako se odzivamo na estetsko doživetje, so precej kasneje začeli raziskovati zlasti angleški raziskovalci na področju vzgoje in izobraževanja. Ugotovili so, da lahko estetsko doživetje in odziv nanj otroka pripelje do tega, da začne ponovno ocenjevati in premišljevati o svojem odnosu, vrednotah in pričakovanjih ter se celo sooča s svojimi predsodki, zato je umetnost lahko moralno vzgojno-izobraževalna (Pike, 2002). Morala in vrednote pa so teme, ki sodijo v koncept državljanske vzgoje oziroma v koncept aktivnega državljanstva. P. Hills-Potter je dokazala, da lahko z uporabo umetniških del pri otrocih spodbujamo sodelovanje v družbi in privzgajamo 
odnos, potreben za aktivno državljanstvo, še posebej empatijo (citirano v Halstead, Pike, 2006, 66).

\section{Državljanska vzgoja in medpredmetno povezovanje}

Politični filozof in teoretik državljanske vzgoje Will Kymlicka trdi, da državljanska vzgoja ne sme biti izoliran sestavni del učnega programa, temveč eden izmed ciljev in načel, ki oblikuje celoten program (Kymlicka, 1999), torej naj bi jo poučevali interdisciplinarno. Nekateri teoretiki pri tem poudarjajo, da morajo biti vsebine usmerjene na določene pojave $\mathrm{v}$ njihovem okolju, da bi moralo povezovanje voditi $\mathrm{k}$ globljemu razumevanju odnosov do sveta in da mora državljanska vzgoja več predmetov povezati $\mathrm{v}$ aktiven projekt, $\mathrm{v}$ katerem bodo otroci videli povezave $\mathrm{z}$ vsakodnevnimi situacijami (Drake, 1998, 154). Interdisciplinarne diskusije učencu omogočajo lažje izražanje lastnih idej in interpretacij ter spodbujajo podajanje različnih mnenj in vidikov (Hickman, Kiss, 2010). Interdisciplinarne povezave omogočajo, da posameznik na svoj način osmisli znanje in spretnosti posameznega področja ter gradi osebni pogled na svet (Beuermann, 2001). Hickmann in Kiss (2010) trdita, da bi z učenjem prenašanja znanja in spretnosti $z$ enega področja na drugo učencem omogočili uporabnost ter celovitejše in globlje razumevanje snovi in učnih konceptov. V raziskavi iz leta 2010 sta avtorja ugotovila pozitivne povezave med interdisciplinarnimi pristopi ter sposobnostjo transferja znanja in spretnosti. Rawding in Wall (1991) sta v kroskurikularni študiji izvedla poizkus medpredmetnega poučevanja religije in umetnosti. $V$ intervjujih s sodelujočimi učenci sta ugotovila, da so nekateri izmed njih odkrili ne le povezave med umetnostjo in verstvi, temveč so začeli integrirati vidike izkušenj in znanj onkraj okvirov šolskih predmetov. Učenci torej niso zgolj uspešno povezali teme dotičnih predmetov, temveč so se naučili koncepta medpredmetnega mišljenja na splošno ter to znanje prenesli tudi na primere drugih predmetov in področij.

Ker danes na vzgojo in izobraževanje gledamo tudi kot na usposabljanje za življenje in ne le za poklic, imajo izkušnje $\mathrm{z}$ umetnostjo $\mathrm{v}$ tem procesu pomembno mesto (Hickman, 2005; Halstead, Pike, 2006, 65). Tako sta Halstead in Pike za državljansko vzgojo relevantno umetnost našla v grafitih in angleškem slikarstvu 18 . stoletja, konkretneje, v Hogartovi seriji Harlots Progress, ki je močno moralno vzgojnoizobraževalna. Predlagata, da se ob upodobitvi zgodbe o revni kmetici, ki je v začetku 18. stoletja prišla v London iskat boljše življenje, postala prostitutka, kmalu umrla za sifilisom, za sabo pa pustila nepreskrbljenega otroka, otroci pogovarjajo o seksualni etiki, zakonu, lokalni avtoriteti, sodobnih oblikah prostitucije, izsiljevanju itd. ter s tem uresničujejo cilje državljanske vzgoje (Halstead, Pike, 2006, 71-74). 
Kljub temu, da se pri nas že vse od osamosvojitve dalje ogromno piše o državljanski vzgoji in aktivnem državljanstvu ter da je bilo na to temo opravljenih že veliko raziskav in projektov, nam še ni uspelo izpeljati niti enega pristopa, ki bi črpal iz umetnosti. Na prvi pogled se zdi to precej nenavadno, saj je umetnost že sama po sebi interdisciplinarna in zato kot nalašč za medpredmetno povezovanje, kot je na primeru grške umetnosti pokazal T. Germ $(2008,43,44)$. Pri vsaki poglobljeni interpretaciji umetnine je namreč potreben interdisciplinarni pristop oziroma mora biti razlaga umetniškega dela večplastna. Ali kot je zapisala L. Tavčar: »[...] poskušamo $\mathrm{v}$ umetnostnih muzejih in galerijah doseči, da mladi obiskovalci ogled umetniških del povežejo $\mathrm{z} v$ šoli pridobljenimi znanji in predmeti, kot so: zgodovina, geografija, umetnostna zgodovina, književnost, glasba itd. Ogledi jim omogočijo, da ta znanja povežejo, ko pod vodstvom muzejskega pedagoga prodirajo $\mathrm{v}$ pomenske plasti umetniškega dela (Tavčar, 2009, 78). S pravo izbiro umetnine iz kateregakoli obdobja pa se lahko navežemo tudi na številne vsebine in cilje državljanske vzgoje.

Vigotski pravi, da je umetnost prvobitno in najmočnejše orožje v boju za obstanek, najpomembnejše stičišče vseh bioloških in socialnih procesov osebnosti v družbi, brez nove umetnosti sploh ne more biti novega človeka (Vigotski, 1975, 327-328). Kakšna je torej danes "nova - sodobna umetnost in kako se povezuje s konceptom aktivnega državljanstva?

\section{Sodobna umetnost kot angažirana družbena praksa}

Umetnost je komunikativna in pomaga ljudem razumeti vidike sveta, ki jih sicer ne bi mogli razumeti. Je osrednja in bistvena človeška in družbena dejavnost, ki lahko tudi šokira, inspirira ter spremeni poglede, ideje in občutke (Stibbs, 1998, 202, 210; Freedman, 2003, xi). Umetnost je družbena praksa, saj umetnik skozi umetniško delo izraža svoj odnos do sebe, drugih in sveta, v katerim živi, zato mora dobro razumeti družbeni ustroj, v katerem deluje (Bourriaud, 2007, 92). Tako je umetnost že sama po sebi povezana s konceptom državljanstva oziroma bi morala postati del vzgoje in izobraževanja vsakega državljana, saj je vir znanja, prepričanj in vrednot o nas samih in o svetu (Dobbs, 1998, 9). S cilji državljanske vzgoje se povezuje, ker poglobljena obravnava umetnine, ki temelji na poststrukturalističnih metodah (Grierson, 2003, 102; Knight, 2010, 240, 241), nujno vsebuje kritično mišljenje ter oblikovanje stališč in vrednot. Poleg zgodovine, geografije in slovenščine je poznavanje evropske in slovenske umetnosti ključnega pomena za ustvarjanje in ohranjanje nacionalne identitete. Delo $\mathrm{z}$ umetnino je povezano $\mathrm{z}$ multikulturnostjo, ki je prav tako ena temeljnih usmeritev vzgoje in izobraževanja, saj če ne poznamo in razumemo svoje kulture, težko vzpostavimo odnos do druge kulture in jo težje razumemo. Poznavanje umetnosti 
številnih kultur pa pomaga razumeti ljudi teh kultur, ne samo njihovih umetniških del (Dobbs, 1998, 11). Obiskovanje muzejev, galerij in drugih javnih prostorov, kjer lahko doživljamo umetniška dela, je del angažiranega družbenega in socialnega delovanja, $\mathrm{k}$ čemur spodbuja državljanska vzgoja. To je v Sloveniji še toliko bolj pomembno, saj so pri nas take ustanove pretežno financirane iz javnega denarja in aktivnega državljana bi moralo zanimati, kakšne dejavnosti finančno podpira. Zato bi moralo biti navajanje na obiskovanje muzejev obvezni del že osnovnošolskega kurikula. Na ta način bi otroke kot bodoče davkoplačevalce navajali na uporabljanje tistega, kar bodo plačevali, tako da bodo do tega, kar plačujejo, tudi vzpostavili kritičen odnos. Če namreč državljani ne čutijo potrebe po produkciji umetniških del, je lahko delovanje takih institucij finančno ogroženo (Halstead, Pike, 2006, 66). Muzeji in galerije s svojo razstavno politiko oblikujejo vrednote, ker pa so te dejavnosti pri nas financirane iz državne blagajne, pričakujemo, da se država sprašuje, katere vrednote prek muzejev kot javnih družbenih institucij podpira. ${ }^{1}$

Sodobna umetnost se precej razlikuje od svoje predhodnice - moderne umetnosti. Moderna umetnost se je hotela osamosvojiti od ideologij, ni hotela biti ilustrativna, umetniki so se imeli za genije, stvaritelje, izumitelje, edini diktat, ki so se ga držali, je bilo iskanje novega in originalnega. Modernisti so se ukvarjali s sliko kot dvodimenzionalno površino, ki je pokrita z barvami, in niso hoteli, da bi prikazovala karkoli drugega, zato se je moderna umetnost zelo odmaknila od družbe. Sodobnih umetnikov pa ne zanima novo ali napredek, ne zanimajo jih točno določene stilne usmeritve, ampak jim je dovoljen pluralizem idej, materialov in medijev, zato je eden bistvenih vidikov sodobne umetnosti heterogenost. Številnim sodobnim umetnikom je skupno, da se hočejo približati življenju, družbi, zato so skozi najrazličnejše likovne prakse začeli govoriti o našem vsakdanjem življenju. Tako se nekateri ukvarjajo z estetiziranjem vsakdanjega življenja, spet drugi vzamejo podobo iz vsakdanjega življenja in jo po svoje interpretirajo. Zaradi novih problemov, s katerimi se ukvarja sodobna umetnost, so začeli umetniki posegati tudi na področja, ki presegajo le formalne in estetske vidike. Predstavitev sodobne umetnosti ni več vezana le na muzeje in galerije, temveč se seli tudi v druge javne prostore, na primer v nakupovalna središča, in s tem privablja publiko, ki sicer ni v stiku z umetnostjo in nikoli ne bi stopila v umetnostni muzej ali galerijo. Številni umetniki bolj kot sami v svojem ateljeju delajo v socialnih in okoljskih situacijah ali v partnerstvu s skupnostmi ali obiskovalci. Številne tako druži, da v svojo produkcijo bolj dejavno vključujejo publiko, da je za razliko skrajno individualizirane estetike (ki je značilna za moderno umetnost) v ospredje stopila kolektivna estetika,

1 Ta problem sicer presega namen tega članka in verjetno bi nanj najbolje odgovorili filozofi oziroma estetiki. Na tem mestu lahko opozorimo le, da sta bila pred razsvetljenstvom glavna podpornika umetnosti Cerkev in plemstvo (ter v manjši meri meščanstvo), ki sta zelo dobro vedela, kaj naročata oziroma plačujeta (glej tudi Žerovc 2011, 13 in Žerovc 2012, 10-12). 
da se ne odmikajo od vsakdanjega življenja in se zapirajo vase, ampak jih zanimajo tudi vse tiste stvari, ki zanimajo vse sodobnike. Umetniki svojega poklica nimajo več za vzvišeno dejavnost, ampak ga primerjajo z drugimi poklici. Tako je sodobna umetnost področje, ki je vpeto $\mathrm{v}$ širši politični, kulturni in družbeni kontekst, se na to vpetost zavestno odziva ter je polje za refleksijo in razmislek o kulturnih in družbenih problemih sedanjosti (Krauss, 1988; Groys, 2002, 11-22; Weintraub, 2003; Millet, 2004, 11-39; Zabel, 2000, 261-264; Zabel, 2005, 6-19). Sodobni umetniki ne težijo več samo k novemu, zato je zares novo v sodobni umetnosti sodelovanje s publiko oziroma socialnim okoljem. V umetniških delih, kjer publika aktivno sodeluje oziroma participira, kjer je publika del umetniškega procesa, ni več važen samo končni produkt, ampak so ta dela najbolj ohranjena $\mathrm{v}$ spominih ljudi, ki so sodelovali pri njih, ali se umetnina dogaja v občutkih ljudi, ki pri njenem nastajanju sodelujejo. Taka dela obiskovalci dokončajo s svojo razlago ali z realnim delovanjem (Millet, 2004, 29-35). Govorimo o relacijski umetnosti (Bourriaud, 2007) oziroma participatornih praksah oziroma socialno angažiranih umetniških praksah (Bishop, 2006; Jackson, 2011; Helguera, 2011), ki so se pojavile v devetdesetih letih prejšnjega stoletja. Sodobni umetniki govorijo tudi o tem, da hočejo s svojo umetnostjo spremeniti pogled ljudi na določen problem. Svetovno znani performer Ulay - Uve Laysipen -, ki se zadnjih pet let intenzivno ukvarja $\mathrm{z}$ vodo in je leta $2012 \mathrm{~s}$ svojim umetniškim delom sodeloval $\mathrm{v}$ Mariboru v projektu Evropska prestolnica kulture, je zapisal: »Moja želja je, da bi podal drugačno idejo, podobo vode. Gre za to, da bi se ljudje zamislili in drugače vrednotili vodo, da bi se sploh počutili povezane z njo« (Pungerčič, 2012). Šejla Kamerić, ki je že večkrat razstavljala v Sloveniji, je v zvezi s svojim mednarodno priznanim delom Bosnian girl, ki bo še omenjeno, zapisala: »Moj cilj ni bil, da se najde nesrečnik, ki je tako neumnost pisal po zidu, temveč da se usmeri pozornost na odgovornost tistih, ki pošljejo popolnoma nedorasle ljudi na konfliktna območja reševat življenja« (Megla, 2012). Sašo Sedlaček je v zvezi s svojim projektom Infokalipsa zdaj!, s katerim je opozarjal na razprodajo javnega frekvenčnega spektra, izjavil: »Ravno pred kratkim smo v parlamentu izvedli akcijo $\mathrm{z}$ naslovom Manifest, da poslance poučimo o pravilih lepega vedenja.« in »Iz tega materiala vselej poskušam narediti nekakšen miselni obrat in stvari ponuditi nazaj javnosti ...« (Tratnik, 2009, 17).

Prav sodobna umetnost za razliko od moderne umetnosti ne diktira sloga in vsebine ter ni enosmerna, pluralistična je tako formalno kot vsebinsko, ponuja različna razumevanja in $s$ tem daje zgled za strpnost in kritično mišljenje. Današnji umetniki se fokusirajo na aktualne socialne, politične ali ekonomske teme, kot so trajnostni razvoj, globalizacija, migracija ali kulturne izmenjave, medtem ko drugi zastavljajo bolj intimna vprašanja o človeških odnosih, spominu, življenju in smrti. Vse to pa so vprašanja, ki zadevajo koncept državljanske vzgoje. Veliko aktualnih 
oziroma sodobnih problemov, ki zadevajo družbo, pa v učnih načrtih ni zajetih in tudi množični mediji ne poročajo o njih. Če vzamemo za primer diskriminacijo, za katero je S. Mihelj pokazala (Mihelj, 2003, 20), da se pri predmetu zgodovina v osnovni šoli o njej sicer govori, a le ob zgledu fašizma in nacizma »okupatorjev«, ne pa o tem, kaj se dogaja sedaj, v času, v katerem trenutno živimo. Dobre razmisleke o diskriminaciji tukaj in zdaj (in tudi v globalnem svetu) pa daje sodobna umetnost, kot bomo videli $\mathrm{v}$ nadaljevanju. Sodobna umetnost se namreč odziva na aktualne probleme prej, kot pridejo v širšo zavest. Sedlačkova akcija Just do it!, v kateri je leta 2003 zazidal vhod v ljubljanski City park z zidaki, izdelanimi iz reklamnih oglasov, pri čemer je tematiziral tako potrošništvo kot odpadke in reciklažo, je nastala, ko je bila Slovenija na višku potrošništva in smo bili večinoma še vsi navdušeni nad obilnim reklamnim materialom, s katerim so trgovci zasipavali naše nabiralnike (Grafenauer, 2011, 2426). Šejla Kamerić je s svojo že omenjeno podobo Bosnian girl polepila stene Sarajeva precej prej, preden je mednarodna skupnost prepoznala, da se je v Srebrenici zgodil genocid nad Bošnjaki (Megla, 2012, 24, 25). Zato nam sodobna umetnost pomaga razumeti sedanjost, v kateri živimo, ponuja uvid v naš družbeni ustroj in nas spodbuja, da ga sooblikujemo. Ker se vsebine sodobnih likovnih praks vežejo na sedanje življenje in globalne probleme, je delo z njimi v multikulturnem okolju lažje, saj ne zahteva znanja o umetnostni tradiciji določenega kulturnega okolja oziroma določene države (na primer poznavanja klasičnih ali krščanskih besedil, kar je potrebno za razumevanje starejše zahodnoevropske umetnosti). Glede na kritike znamenite Hirschove knjige o kulturni pismenosti (Hirsch, 1987; Beck, 1998) je treba biti pri pedagoškem delu z umetninami v multikulturnem okolju previden (Halstead, Pike, 2006, 69).

$\mathrm{V}$ tem kontekstu je treba posebej izpostaviti t. i. participatorne prakse, pri katerih umetnik sam oblikuje posebne skupnosti za določeno umetnino in s tem pravzaprav napoveduje vzpostavitev državi vzporednih skupnosti. Ne le da umetnina sili $\mathrm{k}$ razmišljanju o svoji vsebini (Železnik, 2011, 87), ampak je gledalec sam udeležen pri produkciji umetnine in se umetnina dogaja v njem, v njegovih občutkih, ki jih doživlja ob tem, ko sodeluje. Participatorna praksa je torej prvoosebna izkušnja, saj gledalci soustvarjajo umetnino. Te prakse niso tako neposredno moralno vzgojnoizobraževalne, kot so morda starejše umetnine, če spet izpostavimo Hogarthovo delo, ki ga priporočata Halstead in Pike (2006), ampak nas le pripravljajo na to, da lahko razmišljamo o določenem pojavu, ravnanju ali stvari, oziroma nas, če participiramo, prisilijo, da ob nekem dogodku doživljamo občutke, ki so za nas lahko celo travmatični in ki jih lahko kasneje predelamo sami s sabo ali v pogovoru z drugim. Sodobne participatorne prakse nam tudi omogočajo, da dejanje, ki je moralno sporno, izvršimo na simbolični ravni, tako da to dejanje pripravlja teren za razmišljanje. Tako smo na primer leta 2000 v Koldingu in leta 2006 v Dornbirnu lahko v kuhinjskem mešalniku 
zmleli zlato ribico (Žerovc, 2011, 108). Preden smo se lotili tega dejanja, smo morali temeljito razmisliti, ali bomo to storili ali ne in zakaj - razmišljali smo na primer o našem ambivalentnem odnosu do živali. Torej je participatorna praksa že sama po sebi vzgojno-izobraževalna, saj je zelo podobna pedagoški metodi igre vlog in simulaciji konkretnih življenjskih primerov, ki jih na primer A. Židan priporoča pri izobraževanju in vzgoji za demokracijo (Židan, 2004, 51, 52), Halstead in Pike pa menita, da se morda najbolje naučimo moralnega vedenja, če dobimo priložnost zanj (Halstead, Pike, 2006, 146-148). Pri tem pa je treba poudariti, da pri participaciji v sodobni umetnosti ne gre za narejeno, simulirano igro, ampak za avtentično, pravo igro vlog, ki je gotovo bolj prepričljiva in učinkovita. Če smo vključeni v neki dogodek, morda težje ostanemo ravnodušni, kot če le gledamo podobo, kot predlagata Halstead in Pike (2006, 72-74). V sodobnem svetu namreč ni več dovolj, da se ob neki moralno vzgojno-izobraževalni podobi pogovarjamo. Po mnenju J. Baudrillarda v sedanjem svetu vizualnih podob, računalniške tehnologije in medijskih posebnih učinkov podobe ne povezujemo več $z$ realnim dogodkom, ki ga morda prikazuje, saj simulakri ustvarjajo lastno resničnost ter je zveza med referentom in znakom prekinjena (Baudrillard, 1999, 143-149; Erjavec, 1996, 30-34), zato je morda bolj učinkovito participirati v sodobnem likovnem delu ter tako soustvarjati in sodoživljati umetnino. Te participatorne prakse skoraj nikoli niso individualne, temveč so kolektivne, kar udeležence že samo po sebi nagovarja, da po dogodku izmenjujejo občutke in mnenja.

Ker še nimamo metodologije za vrednotenje sodobne umetnosti (Millet, 2004, 66), si lahko pri njenem razumevanju oziroma pedagoški interpretaciji morda še najbolje pomagamo s poststrukturalističnimi metodami, $\mathrm{v}$ katerih se prepletajo različne vede in stroke in ki nam približujejo tudi vprašanja o nas samih (Kdo smo? Od kod prihajamo? Kam gremo?) in ki skušajo vplesti tudi obiskovalčeva čustva in domišljijo (Larcher in Hooper-Greenhill, citirano v Tavčar, 2001, 26). Ena takšnih je Ways In, ki jo že dolgo uporabljajo v galeriji Tate. Metoda sestoji iz štirih interpretativnih okvirjev, pri čemer je prvi okvir osebni pristop. Vloga mentorja oziroma spremljevalca ni $\mathrm{v}$ tem, da frontalno razlaga, ampak da usmerja pogovor, spodbuja učence $\mathrm{k}$ pogovoru, $\mathrm{k}$ izražanju mnenj in poslušanju mnenj drugih. Ob tem se glavna vprašanja nanašajo na učenca, njegov svet in njegove izkušnje (Kakšna je moja prva reakcija na umetniško delo? Zakaj se tako počutim, zakaj tako razmišljam? Kako na to vplivajo moj spol, rasa, starost, socialno ozadje, geografski izvor, družina, dom? Kako moj odziv odseva moj odnos, vrednote in prepričanja? Kako se moje mnenje spreminja med pogovorom z drugimi? Na kaj me spominja to delo in zakaj? Ali so moji odgovori podobni odgovorom mojih sošolcev? Kako je moje dojemanje prežeto $\mathrm{z}$ mojimi predhodnimi izkušnjami?) (Charman, Rose, Wilson, 2006, 54-56). Ob teh pogovorih torej ne spoznavajo le umetnine, ampak tudi sebe in drug drugega ter gojijo razumevanje do 
stališč in mnenj svojih vrstnikov. Ob pogovoru o sodobni umetnosti učenci razvijajo zmožnost artikuliranja idej v skupini, kar spodbuja tudi k spoštovanju idej drugih. Ko se učenci pogovarjajo o sodobni umetnosti, se pogovarjajo o kontekstu, v katerem je umetnina nastala, o ideji, ki jo nosi umetnina, in o tem, zakaj je nastala, torej o svetu, v katerem živijo. Tako si širijo horizont, se sprašujejo in diskutirajo o sodobnih problemih, ki jih imajo sami, ter prepoznavajo probleme sodobne družbe. Vse našteto so tudi cilji državljanske vzgoje.

V nadaljevanju poglejmo, kakšni so ti cilji. Državljanska vzgoja oziroma koncept aktivnega državljanstva je v gimnazijah integriran v različne humanistične in družboslovne predmete, eksplicitno pa se udejanja v obveznih izbirnih vsebinah. Analizirala bom cilje in vsebine teh vsebin in ugotavljala povezljivost $\mathrm{z}$ vsebinami, ki jih tematizira sodobna umetnost.

\section{Povezljivost vsebin sodobne umetnosti z obveznimi izbirnimi vsebinami}

Vsebine sodobnih umetniških praks, ki sem jih navedla zgoraj, se lahko povezujejo tako z vsebino Državljanska kultura kot z vsebino Vzgoja za mir, družino in nenasilje. Pri vsebini Državljanska kultura se lahko povezujejo kar trije izmed štirih navedenih ciljev, in sicer: "širitev znanja in usposabljanja za kritično analizo sodobne slovenske družbe, razvijanje miselnih in izraznih sposobnosti, uporaba pojmov in kategorij, sintetiziranje idej«, »razvijanje stališč in obnašanj, ki so primerna za vključevanje $\mathrm{v}$ družbo, vzpodbujanje vrednot demokratične politične kulture: vzpodbujanje kritičnosti, tolerance, sposobnosti argumentiranja « in »razvijanje zavesti o civilizacijskih, družbenih in drugih problemih ter ob tem razvijanje zmožnosti samostojnega presojanja«. Z vsebinami sodobnih likovnih praks se povezujejo vsaj vsebine, ki so navedene pod skupnim naslovom Posameznik, družba, država; to so "vprašanja človekovih pravic in svoboščin, politična svoboda, konflikt med parcialnimi in večinskimi interesi, smisel državne/občinske regulacije, poštenje, tolerantnost, narodna identiteta, patriotizem«. Pri metodah dela sta poleg drugih navedeni »skupinske diskusije« in »različne dejavnosti, povezane s širšo lokalno skupnostjo«, priporočena pa je tudi interdisciplinarnost. Vsebine sodobnih umetniških praks povezujejo tudi z nekaterimi cilji vsebine Vzgoja za mir, družino in nenasilje, saj je med cilji zapisano tudi: „dijakom omogočimo boljše spoznavanje in osebnostno zorenje «, »dijaki se naučijo svoja osebna doživetja in izkušnje povezovati z družbenimi normami «, »dijaki spoznajo, da je treba posameznika razvijati v svobodno, miroljubno, strpno, odgovorno in nenasilno osebnost «, »dijaki analizirajo in interpretirajo procese in pojave (nasilje, netoleranca, ksenofobija, rasizem, predsodki, zapostavljenost ..., 
načine preseganja problemov) «, »dijaki utemeljujejo in oblikujejo svoje lastne sklepe na osnovi racionalnih argumentov«, »razvijanje spretnosti: analitično mišljenje, komunikacijske tehnike (dialog, argumentacija ...), kooperacija«. Te cilje udejanjamo prek vsebin, kot so Procesi socializacije in nenasilje ter Kultura miru, pri čemer lahko naštejemo vse alineje: "samospoštovanje in dostojanstvo posameznika, odgovornost do ljudi in okolja, nenasilno delovanje v zgodovini, vzgoja za mir in razumevanje med narodi $\mathrm{v}$ mednarodnih dokumentih, načela mednarodnega zaupanja, sožitja in odgovornosti kot pogoj za mirno reševanje sporov v mednarodni skupnosti (aktualni mednarodni dogodki)«. Tudi pri teh vsebinah sta priporočeni interdisciplinarnost in medpredmetnost, kot metoda dela pa igra vlog (Obvezne izbirne vsebine, 2010). V priporočilih pri obeh vsebinah torej dobimo namig, da lahko cilje in vsebine obveznih izbirnih vsebin udejanjamo v pogovoru o sodobni umetnosti ter tako cilje in vsebine Državljanska kultura in Vzgoja za mir, družino in nenasilje povežemo s Kulturnoumetniškimi vsebinami. Pri tej vsebini cilji niso izraženi, pod vsebinami pa najdemo tudi: »srečanje $\mathrm{z}$ umetniki [...] in pogovor o njihovem ustvarjalnem delu«, »pripravljeni in vodeni obiski likovnih razstav in srečanje z likovnimi umetniki« (Obvezne izbirne vsebine, 2010).

Ob tem se nam najprej zastavi vprašanje, ali gimnazijci sploh pridejo v stik $\mathrm{s}$ sodobno umetnostjo in na kakšen način je obravnavana oziroma na kakšen način jim je predstavljena. Pri obveznem delu učnega načrta imajo za to v gimnazijah malo možnosti. Sodobna umetnost je vključena v enega izmed dveh delov predmeta Likovna umetnost. Delu z naslovom Umetnostna zgodovina je namenjenih 35 ur, razdeljen pa je na osem poglavij. Spoznavanje sodobne umetnosti je cilj osmega poglavja, in če bi bilo vsem poglavjem namenjeno enako število ur, bi to pomenilo, da so spoznavanju sodobne umetnosti namenjene dobre štiri ure. Torej se lahko upravičeno vprašamo, koliko je sploh možnosti za to oziroma ali te vsebine sploh pridejo na vrsto. Zato je toliko bolj pomembno, da se izkoristijo ure, ki so namenjene spoznavanju kulturnoumetniških vsebin $\mathrm{v}$ okviru obveznih izbirnih vsebin. Posamezni vsebini je $\mathrm{v}$ okviru obveznih izbirnih vsebin namenjenih 15 ur, in če bi združili vse tri vsebine, torej Kulturno-umetniške vsebine, Državljanska kultura in Vzgoja za mir, družino in nenasilje, in jih medpredmetno povezali, kakor tudi priporoča učni načrt, bi tako dobili kar 45 ur.

\section{Trije primeri: Proletarci vseh dežel, Žicar, EU/Others}

Za ponazoritev možnega povezovanja sodobnih likovnih praks in obveznih izbirnih vsebin vzemimo le dva cilja, ki sta sicer med seboj povezana. To sta »vzpodbujanje tolerance« (cilj vsebine Državljanska kultura) ter »dijaki analizirajo 
in interpretirajo procese in pojave (nasilje, netoleranca, ksenofobija, rasizem, predsodki)«(cilj vsebine Vzgoja za mir, družino in nenasilje). Pri izbiri cilja sem izhajala iz ugotovitve raziskovalcev v projektu Primerjalna raziskava državljanskega izobraževanja in vzgoje - cep (raziskava, ki je potekala leta 1999, je zajela učence iz 28 držav), ki pravi, da imajo slovenski učenci do priseljencev pomembno manj naklonjen odnos, kar po mnenju raziskovalcev vzbuja skrb in terja nadaljnje analize (Pedagoški inštitut, 2002). ${ }^{2}$ Mladinske in javnomnenjske raziskave $\mathrm{v}$ zadnjih petnajstih letih tudi kažejo, da mladino bolj kot vrednote, vezane na močne ideologije (politika, religija, nacionalna zavezanost), zanimajo vrednote, ki so bližje posamezniku in njegovemu osebnemu izkustvu (materialna in socialna varnost, prijateljstva in odnosi, zdravje in zdravo okolje, kvaliteta vsakdanjega življenja, samorealizacija) (Ule, 2008, 90-92).

Umetnost je lahko v preteklosti tudi sama generirala predsodke. Tako lahko na primer ob reliefni upodobitvi timpanona portala cerkve sv. Magdalene v Vézelayu iz leta 1130 razmišljamo in se pogovarjamo o diskriminaciji oziroma odnosu do drugega. Upodobitev kaže Kristusa, ki apostolom naroča, naj širijo krščansko vero po vsem svetu. Na prekladi portala so upodobljeni tisti ljudje, ki misije širjenja vere še niso sprejeli; ti so upodobljeni kot "polljudje« - nekateri imajo prašičje rilce, drugi slonja ušesa, spet tretji so pritlikavci. Gre torej za utrditev podobe o nevernikih v času križarskih pohodov, pri katerih je ta cerkev imela pomembno vlogo. V 20. stoletju pa so se predstavitve rasnih razlik in drugačnosti preselile $\mathrm{v}$ popularno kulturo in še vedno niso izginile. Tako $\mathrm{v}$ zahodnoevropski in ameriški popularni kulturi prevladujejo upodobitve temnopoltih, ki temeljijo na podobah, ki so se izoblikovale v obdobju imperializma poznega 19. stoletja. Te podobe so bodisi negativne bodisi na videz pozitivne (stereotipni pozitivni liki), v najboljšem primeru pa ambivalentne (Hall, 2010).

A veliko sodobnih umetnikov se tega problema loteva na drugačen način, saj se ukvarjajo s tem, kako (stereotipne) predstave o drugih spremeniti, oziroma nas silijo $\mathrm{k}$ razmišljanju o tem, ali so naše predstave o drugih pravilne ali ne. Umetnine ne kažejo več stereotipnih predstav o drugih, ampak simbolične meje med »normalnim» in "deviantnim», med "normalnim» in "patološkim», med »sprejemljivim» in »nesprejemljivim «, med "mi« in »oni«, kot je stereotipiziranje opredelil Hall (Hall, 2010, 258, 259), brišejo, nas opozarjajo, da drugi sploh obstajajo, saj smo jih do sedaj popolnoma ignorirali, ali pa nam kažejo naš diskriminatoren odnos do »drugih«.

Za ponazoritev bom med njimi izbrala le tri umetnike oziroma njihove umetnine oziroma umetniške dogodke, ki smo jih v Ljubljani lahko videli v zadnjem desetletju. Izhajam namreč iz prepričanja, da je stik z originalnimi umetniškimi deli ključnega

2 V drugi mednarodni primerjalni študiji, ki je bila opravljena deset let kasneje (2009), sicer slovenski učenci niso več odstopali v negativni smeri in so se uvrstili v mednarodno povprečje (Šimenc 2012, 96). 
pomena za vse, ki proučujejo in ustvarjajo umetnost, razmišljajo o njej ali se ukvarjajo z njo (Charman, Rose, Wilson, 2006; Talboys, 2010). To prav gotovo še toliko bolj velja za participatorne likovne prakse, saj se umetnina, kot sem že napisala, dogaja v nas in umetniškega dogodka prek reprodukcije sploh ne moremo doživeti. Ob umetninah, ki so sicer večpomenske in mnogoplastne oziroma njihovih pomenov ni mogoče nikoli dokončno fiksirati, bom izpostavila le tisti del vsebine, ki ga lahko povežemo s prej omenjenima ciljema.

Jeseni leta 2011 smo lahko na 29. ljubljanskem grafičnem bienalu, ki je bil posvečen umetniškemu dogodku, participirali pri umetnini umetnika turškega rodu Serkana Özkaya, ki živi in dela v New Yorku in Istanbulu. V instalaciji z naslovom Proletarci vseh dežel je bilo na tla galerije prilepljenih na tisoče majhnih figur delavcev iz rdeče plastične pene $z$ značilno delavsko dvignjeno roko, stisnjeno v pest (Žerovc, 2011, 142, 143). Figurice so bile po prostoru razporejene tako na gosto, da se obiskovalec ni mogel izogniti stopanju po njih, če je hotel oditi v naslednjo dvorano galerije. Obiskovalec se je tako po delavskem razredu sprehodil nalahno ali pa je dolgo skakal po njem, saj so se prilepljene figurice iz prožne pene vsakokrat postavile nazaj na noge. A ob koncu razstave so nekateri delavci le »klonili« pod težo tistih, ki so jih tlačili k tlom. Ta postavitev je nekatere obiskovalce tako pretresla, da se sploh niso odločili, da bi stopili $\mathrm{v}$ naslednjo dvorano, ker jim je bilo tudi na simbolni ravni preveč težko tlačiti delavca. Drugi so po figuricah stopali nalahno, kot bi stopali bosi po steklu, nekateri pa so prav uživali v skakanju. Umetnik nas je tako na sicer precej duhovit način napeljal na možnost, da razmišljamo o problematiki sodobnega proletariata in njegovega mesta $\mathrm{v}$ družbi.

Drugo umetniško delo je Žicar Saša Sedlačka, ki se je leta 2006 sprehajal po ljubljanskem City parku, po ulicah Tokia in Tajpeja, leto kasneje so ga uporabljali ljubljanski brezdomci, lani pa smo ga lahko videli na retrospektivni razstavi v Ljubljani. Glavne teme Saša Sedlačka, ki velja za eno osrednjih imen sodobne umetnosti na Slovenskem, so odpadki, recikliranje in odnos do drugega $\mathrm{v}$ globaliziranem svetu. $\mathrm{Na}$ probleme sodobne družbe ne le opozarja, ampak ponuja tudi (umetniške) rešitve. Za Žicarja je prejel več nagrad v tujini, pa tudi slovensko nagrado OHO (Tratnik, 2009; Grafenauer, 2011). Žicar je robot, sestavljen iz odpadne računalniške tehnologije. Leta 2006 je v City parku, kjer socialno ogroženim sicer ni dovoljeno prosjačiti, mimoidoče $\mathrm{v}$ polomljeni slovenščini prosil za denar. Robot je bil pri zbiranju denarja zelo uspešen, saj je na uro zbral več kot 1.000 takratnih slovenskih tolarjev. Projekt je pokazal, da veliko raje kot $\mathrm{v}$ človeško dlan damo v integrirana vezja, robotu smo plačali za zabavo, užitek, ki nam ga ponuja njegova tehnologizirana človeškost. Žicar je bil posebej privlačen za mamice z majhnimi otroki, ki se klošarjem ponavadi izogibajo. Podobna je bila reakcija prebivalcev Tajpeja. Tam je bil Žicar, ki je kmalu pritegnil pozornost 
številnih mimoidočih, postavljen poleg berača, ki je ostal osamljen. Po prihodu policista je moral berač oditi, robot pa je lahko ostal (Grafenauer, 2011, 30-33).

$\mathrm{V}$ okviru mednarodnega bienala za sodobno umetnost Manifesta, ki se je leta 2000 pod naslovom Borderline sindrom odvijal v Ljubljani, je Šejla Kamerić postavila instalacijo EU/Others. Rojena Sarajevčanka je postala mednarodno prepoznavna z delom Bosnian girl iz leta 2003, ki prikazuje Kamerićevo samo, ko gleda gledalca, preko njene podobe pa je reproduciran grafit, ki naj bi ga mirovni vojak Združenih narodov napisal v Srebrenici na steno kasarne. S tem je hotela opozoriti na predsodke do drugih ljudi in potrebo, da se jih osvobodimo. V Ljubljani je dala na Tromostovju namestiti napise, ki so bili v tistem obdobju sestavni del mej evropske unije: EU citizens in Others. Danes za Others uporabljamo bolj korekten napis noneuropean citizens. Takrat pa je bil to za umetnico, kot sama pravi, popoln šok, saj je lahko kot državljanka Bosne in Hercegovine brez vizuma potovala le v peščico držav. To je pri njej sprožilo vprašanje identitete, kdo so ti »drugi« in kaj kot »druga« počne na evropskem bienalu sodobne umetnosti v Ljubljani. V času instalacije smo namreč tudi državljani Slovenije na evropskih mejah imeli status »drugih« (Kamerić, 2000).

Že samo ti trije primeri potrjujejo Vigotskijevo tezo, da lahko "nova« umetnost daje ogromno priložnosti za »novega« človeka. Povedano drugače, $\mathrm{z}$ vidika današnjih okoliščin: sodobna umetnost nam kaže pot naprej, pot iz krize (okoljske, medosebne, krize vrednot itd.). Sodobno umetnost je le treba spremljati, jo razumeti in doživljati.

\section{Sklep}

Če se bo koncept aktivnega državljanstva v prihodnosti prilagajal globaliziranemu in multikulturnemu svetu, če se bo ukvarjal z ekonomsko, politično in socialno neenakostjo ne le znotraj nacionalne države, ampak med državami, pri čemer bodo eden izmed etičnih temeljev univerzalne človekove pravice, to se pravi vzgoja za globalno državljanstvo (Židan, 2007, 14; Pikalo, 2010, viii; Demaine, 2010; Davies, Evans Ried, 2010, 217), bo poznavanje, razumevanje in doživljanje sodobne umetnosti še kako aktualno oziroma potrebno. Analiza je pokazala, da lahko prek spoznavanja vsebin sodobne umetnosti uresničujemo cilje aktivnega državljanstva oziroma državljanske vzgoje, ki so integrirani v obvezne izbirne vsebine. Sodobna umetnost je namreč ena izmed panog, ki prepoznava in opozarja na aktualne probleme, o katerih množični mediji ne poročajo. Prepoznava jih, ko so šele v nastajanju, in že predvideva posledice. Zato je zelo pomembno, da imajo dijaki čim več avtentičnega stika s sodobno umetnostjo ter da pedagogi pri tem uporabljajo sodobne metode za doživljanje in razumevanje umetnin. Sodobno umetnost namreč težje kot starejšo 
umetnost poučujemo $\mathrm{v}$ razredu, saj umetniškega dogodka, v katerem aktivno participiramo, ne moremo doživeti v reprodukciji. Zato bi moralo biti obiskovanje galerij, muzejev in drugih prostorov, kjer se prezentira sodobna umetnost in odvijajo umetniški dogodki in kjer se bodo učenci lahko na avtentičen način učili aktivnega državljanstva, precej bolj razvito. S povezovanjem vsebinskih sklopov obveznih izbirnih vsebin Državljanska kultura, Kulturno-umetniške vsebine ter Vzgoja za mir, družino in nenasilje pa bi pridobile vse vsebine. Povezane nam nudijo ogromno priložnosti - kar 45 ur - za poglobljeno obravnavanje sodobne umetnosti in prek nje tem koncepta državljanske vzgoje. $\mathrm{Z}$ vidika medinstitucionalnega povezovanja pa se zastavlja vprašanje o usposobljenosti učiteljev na eni in muzejskih pedagogov na drugi strani. Tu bi pričakovali, da se bodo galerije in muzeji, ki predstavljajo sodobno umetnost, bolj potrudili pri privabljanju šolskih skupin, za učitelje pripravili gradiva o umetninah, umetnikih in s šolskimi kurikuli povezanih vsebinah ter učitelje vpeljevali v nove in drugačne metode dela, ki spodbujajo interdisciplinarnost. Poleg umetnika namreč le kustos, ki pripravlja razstavo, najbolje pozna umetniško delo, ki se dogaja tukaj in zdaj. Ti umetniki namreč še niso valorizirani in zato tudi še ni virov, s katerimi bi si učitelj pomagal, prav tako še niso dostopne reprodukcije. A kustosi sodobne umetnosti se pri nas te pedagoške vloge premalo zavedajo. Tako je, kot je za angleško vzgojo in izobraževanje pred desetletjem ugotavljal Pike (2002), potencial umetnosti tudi pri nas še povsem neizkoriščen. Če bi se z dijaki na primeren način poglobljeno pogovarjali o sodobni umetnosti, bi ti imeli veliko možnosti, da bi spremenili stereotipne predstave ne le o drugih, pač pa tudi o sebi. Lahko bi postali bolj kritični, ozaveščeni in strpni oziroma manj nasilni, ksenofobični in rasistični.

\section{Literatura}

Baudrillard, J., Simulaker in simulacija; Popoln zločin, Ljubljana 1999.

Beck, J., Morality and Citizenship in Education, London 1998.

Beuermann, D., Oblikovanje povezav med umetnostnimi predmeti in šolskim razvojnim načrtom, Vzgoja in izobraževanje 32, št. 4, 2001, str. 32-37.

Bishop, C., Participation. Documents of Contemporary Art, London 2006.

Bourriaud, N., Relacijska estetika. Postprodukcija: kultura kot scenarij: kako umetnost reprogramira sodobni svet, Ljubljana 2007.

Charman, H., Ross, M., Contemporary Art and the Role of Interpretation. Tate Papers, Autumn 2004, http://www.tate.org.uk/research/tateresearch/ tatepapers/04autumn/charman.htm [15. 10. 2012].

Charman, H., Rose, K., Wilson, G., The Art Gallery Handbook: A Resource for Teachers, London 2006. 
Davies, I., Državljanska vzgoja in poučevanje in učenje zgodovine, v: Državljanska vzgoja pri pouku zgodovine, geografije in slovenščine (ur. Justin, J., Sardoč, M.), Ljubljana 2003, str. 45-62.

Davies, I., Evans, M., Reid, A., Globalizacija državljanske vzgoje?, v: Državljanstvo in globalizacija: $k$ državljanski vzgoji za sodobni svet (ur. Pikalo, J.), Ljubljana 2010, str. 207-238.

Demaine, J., Globalizacija in državljanska vzgoja, v: Državljanstvo in globalizacija: $k$ državljanski vzgoji za sodobni svet (ur. Pikalo, J.), Ljubljana 2010, str. 147-164.

Dobbs, S. M., Learning in and through Art: A Guide to Discipline-Based Art Education, Los Angeles 1998.

Drake, S. M., Creating Integrated Curriculum, California 1998.

Erjavec, A., K podobi, Ljubljana 1996.

Freedman, K., Teaching Visual Culture: Curriculum, Aesthetics and the Social Life of Art, New York 2003.

Gaber, S., Vigotski, sociologija, učenje in poučevanje - skica, v: Vigotski, L. S., Mišljenje in govor, Ljubljana 2010, str. 401-426.

Germ, T., Koordinatorji kulturne ali koordinatorji umetnostne vzgoje?, v: Kultura in umetnost v izobraževanju - popotnica 21. stoletja (ur. Požar Matijašič, N., Bucik, N.), Ljubljana 2008, str. 39-46.

Grafenauer, P., Velika prostovoljna čistilna akcija: Sašo Sedlaček!, v: Sašo Sedlaček, Supertrash, Ljubljana 2011, str. 22-46.

Grierson, E., Framing the Arts in Education: What is Really at Stake?, v: The Arts in Education: Critical Perspectives from Aotearoa New Zealand (ur. Grierson, E. in drugi), Palmerston North 2003, str. 93-118.

Groys, B., Teorija sodobne umetnosti: Izbrani eseji, Ljubljana 2002.

Hall, S., The Spectacle of the »Other«, v: Representation: Cultural Representations and Signifying Practices (ur. Hall, S.), London 2010, str. 223-290.

Halstead, J. M., Pike, M. A., Citizenship and Moral Education: Values in Action, London 2006.

Helguera, P., Education for Socially Engaged Art: a Materials and Techniques Handbook, New York 2011.

Hickman, R., Introduction, v: Critical Studies in Art and Design Education (ur. Hickman, R.), Bristol in Portland 2006, str. 15-18.

Hickman, R., Kiss, L., Cross-Curricular Gallery Learning: A Phenomenological Case Study, International Journal of Art \& Design Education 29, št. 1, 2010, str. 27-36. 
Hirsch, D. E., Cultural Literacy: What Every American Needs to Know, Boston 1987.

Jackson, S., Social Works. Performing Art, Supporting Publics, New York, London 2011.

Kamerić, Š., From the e-mail to Katherin Rhomberg, 2000, http://www.sejlakameric. com/art/eu_others_text.htm [15.10.2012].

Knight, L., Why a Child Needs a critical Eye, and Why the Classroom is Central in Developing it, International Journal of Art \& Design Education 29, št. 3, 2010, str. 236-243.

Krauss, R., The Originality of the Avant-Garde and Other Modernist Myths, Cambridge, London 1988.

Kymlicka, W., Education for Citizenship, v: The School Field: International Journal of Theory and Research in Education 10, št. 1-2, 1999, str. 9-36.

Marjanovič Umek, L., Pojmovanje otroka v sociokulturni teoriji Vigotskega, v: Vigotski, L. S., Mišljenje in govor, Ljubljana 2010, str. 373-400.

Megla, M., Šejla Kamerić, vizualna umetnica: Umetnost ni samo za privilegirane, Delo, sobota, 5. maja 2012, str. 24, 25.

Mihelj, S., Povezave učnega načrta državljanske vzgoje in etike z učnimi načrti slovenščine, zgodovine in geografije, v: Državljanska vzgoja pri pouku zgodovine, geografije in slovenščine (ur. Justin, J., Sardoč, M.), Ljubljana 2003, str. 19-23.

Millet, C., Suvremena umjetnost, Zagreb 2004.

Pedagoški inštitut, Primerjalna raziskava državljanskega izobraževanja in vzgoje - cep, 2002, http://www.pei.si/Sifranti/ResearchProject.aspx?id=16 [15. 10. 2012].

Pikalo, J., Predgovor: Državljanska vzgoja za sodobni svet, v: Državljanstvo in globalizacija: $k$ državljanski vzgoji za sodobni svet (ur. Pikalo, J.), Ljubljana 2010, str. VII-IX.

Pike, M. A., Aesthetic Distance and Spiritual Journey: Educating for Morally and Spiritually Significant Across the Art and Literature Curriculum, International Journal of Children's Spirituality 7, št. 1, 2002, str. 9-21.

Pungerčič, B., Ulay - Uve Laysipen: „Deliti z drugimi in skrbeti tudi zanje, ne samo zase«, 2012, http://www.zivljenjenadotik.si/info/tekst/prikaz/article/ulay-uvelaysipen-deliti-z-drugimi-in-skrbeti-tudi-zanje-ne-samo-zase/ [15. 10. 2012].

Rawding, M., Wall, B., Art and Religion in the Classroom: a Report on a Crosscurricular Experiment, Journal of Art \& Design Education 10, št. 3, 1991, str. 293306.

Stibbs, A., »Language in art and art in language«, Journal of Art \&Design Education 17, št. 2, 1998, str. 201-209. 
Šimenc, M. (ur.), Razvoj državljanske vzgoje v republiki Sloveniji: Konceptualni okvir in razvoj kurikulumov, Ljubljana 2012, http://www.pei.si/UserFilesUpload/ file/digitalna_knjiznica/Dissertationes_22_ISBN_978-961-270-147-5_SWF/ ISBN_978-961-270-147-5.html [5. 2. 2013].

Talboys, G. K., Using Museums as an Educational Resource: An Introductory Handbook for Students and Teachers, Farnham in Burlington 2010.

Tavčar, L., Otroci, mladostniki in odrasli v galeriji. Priročnik za kustose pedagoge, učitelje, vzgojitelje in starše, Ljubljana 2001.

Tavčar, L., Homo spectator. Uvod v muzejsko pedagogiko, Ljubljana 2009, http://www. pei.si/UserFilesUpload/file/digitalna_knjiznica/Dissertationes_3/index.html [11. 1. 2013].

Tratnik, P., Brkljanje, ki sproti rešuje probleme, Maska: Časopis za scenske umetnosti 24, 2009, str. 119-120.

Obvezne izbirne vsebine, Zavod za šolstvo, 2010, http://portal.mss.edus.si/msswww/ programi2010/programi/gimnazija/obvezne_izbirne_vsebine.htm [10. 1. 2013].

Učni načrt: Gimnazija: Likovna umetnost, Ljubljana 2008.

Ule, M., Mladi, kultura, vzgoja, v: Kultura in umetnost v izobraževanju - popotnica 21. stoletja (ur. Požar Matijašič, N., Bucik, N.), Ljubljana 2008, str. 89-98.

Vigotski, L. S., Psihologija umetnosti, Beograd 1975.

Weintraub, L., Making Contemporary Art: How Today's Artists Think and Work, London 2003.

Zabel, I., Manifesta 3: Poročilo, Zbornik za umetnostno zgodovino, n. v., 36, 2000, str. 261-294.

Zabel, I., »Sodobna umetnost «, v: 95'05. Teritoriji, identitete, mreže: Slovenska umetnost 1995-2005 (ur. Španjol, I., Zabel, I.), Ljubljana 2005, str. 6-19.

Železnik, A., Sodobna umetnost, političnost in trajnostni razvoj, v: Trajnostni razvoj kot načelo vzgoje in izobraževanja pri likovni in glasbeni vzgoji ter filozofiji (ur. Flajšman, B.), Ljubljana 2011.

Žerovc, B., Marko Evaristti, v: Dogodek. The event, 29. Grafični bienale. The $29^{\text {th }}$ Biennal of Grafic Arts. 23. september-20. november 2011. 23 September-20 November 2011 (ur. Kisin, P., Žerovc, B.), Ljubljana: Mednarodni grafični center, str. 108.

Žerovc, B., Serkan Özkaya, v: Dogodek. The event, 29. Grafični bienale. The $29^{\text {th }}$ Biennal of Grafic Arts. 23. september-20. november 2011. 23 September-20 November 2011 (ur. Kisin, P., Žerovc, B.), Ljubljana: Mednarodni grafični center, str. 142, 143.

Žerovc, B., O umetniškem dogodku na umetnostnem dogodku, v: Dogodek. The event, 29. Grafični bienale. The 29 $9^{\text {th }}$ Biennal of Grafic Arts. 23. september-20. november 2011. 
23 September-20 November 2011 (ur. Kisin, P., Žerovc, B.), Ljubljana: Mednarodni grafični center, str. 13-21.

Žerovc, B., Zakaj na likovnem področju razmišljati o umetniških dogodkih?, Maska: Časopis za scenske umetnosti 27, 2012, str. 10-15.

Židan, A., Za kakovostnejša družboslovna znanja: didaktični in znanstveni prispevki. Ljubljana 2004.

Židan, A., Vzgoja za evropsko demokracijo, Ljubljana 2007. 
Metoda Kemperl

\section{Contemporary art and compulsory elective contents}

Keywords: contemporary art, participatory art practices, socially-engaged art, citizenship education, active citizenship, compulsory elective contents, crosscurricular links

Contemporary art differs from modern art, which preceded it, in that it strives for a return to society and everyday life, while concerning itself with current issues that the individual faces in the here and now. One of contemporary art's more common topics is sustainable development, along with the accompanying issues of environment, values, relation to others, etc. All of these topics are simultaneously part of the concept of active citizenship, which is why understanding contemporary art calls for active citizenship. This is particularly true of relational art, which demands the viewer's active participation. A link between contemporary art and elective high school subjects or topics can be achieved by means of intensive inter-institutional linking of schools and galleries and museums that exhibit contemporary art.Using three examples of participatory practices (Proletarians of All Countries, Beggar Robot and EU/Others), this paper points to potential cross-curricular links in terms of subject matter. It draws attention to the fact that, from an often-overlooked pedagogical perspective, we experience contemporary art in the here and now; it also points out that the poststructural approaches are most conducive to the appreciation of contemporary art. 